\title{
MÉTODO SIMPLIFICADO DE CONCEPÇÃO DE VÍDEOS PARA YOUTUBE NA PRODUÇÃO DE UMA ANIMAÇÃO 3D PARA O COMBATE AO AEDES AEGYPTI.
}

\section{SIMPLIFIED METHOD FOR YOUTUBE VIDEOS DESIGN IN A 3D ANIMATION PRODUCTION FOR COMBATING AEDES AEGYPTI.}

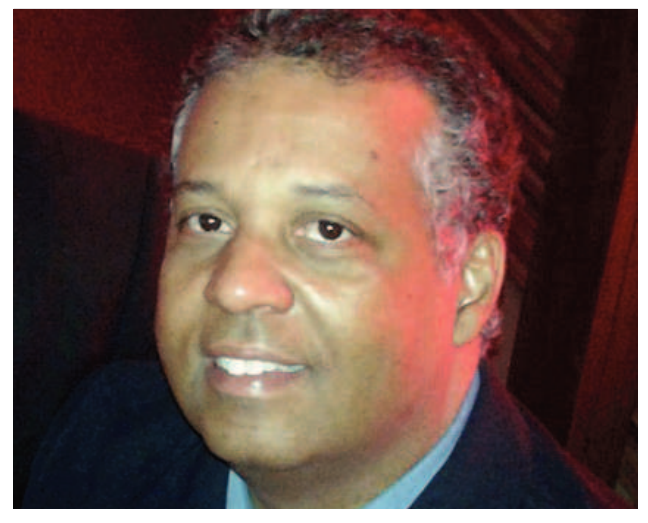

\section{Marcelo Geraldo Teixeira}

Doutor pela Universidade Federal da Bahia

DeVry Brasil

Professor de Design na Faculdade Ruy Barbosa -

Departamento de Design

marcelomgt@gmail.com

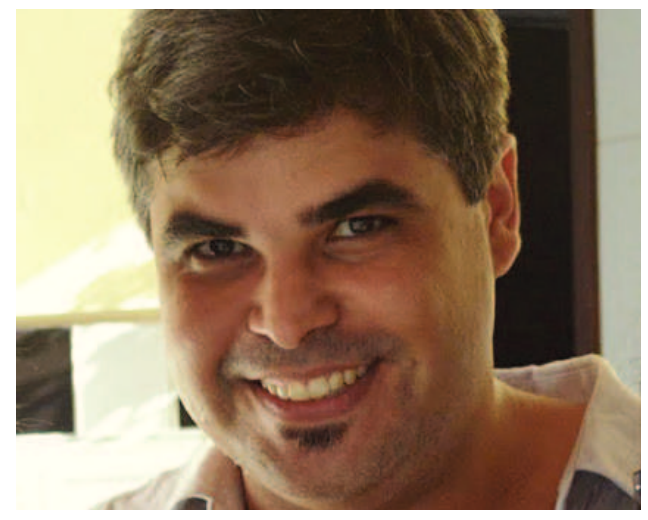

\section{Amaury Moura de Aquino}

Graduado no curso de Produção Multimídia pelo Centro Universitário Jorge Amado (Unijorge)

amauryaquino@hotmail.com

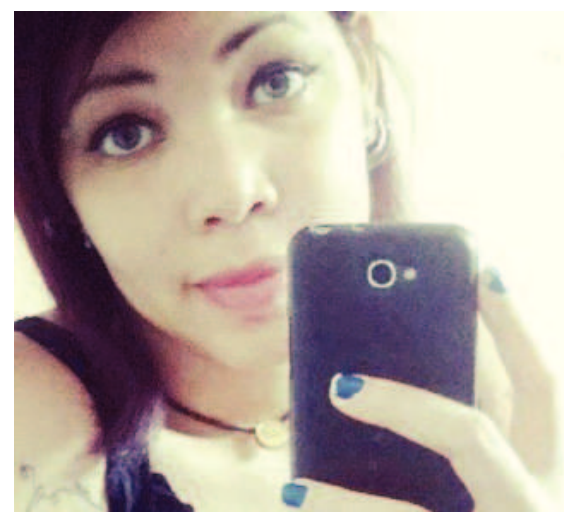

\section{Larissa da Cruz Rosario}

Graduada no curso de Produção Multimídia pelo Centro Universitário Jorge Amado (Unijorge) larosalive@gmail.com 


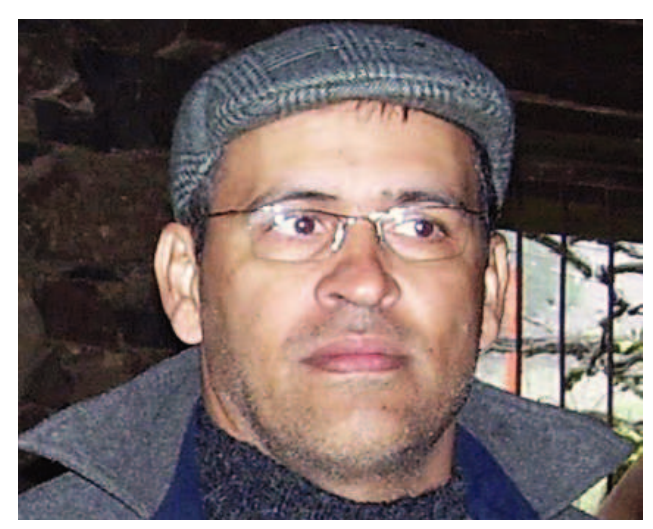

\section{Lucio Bouvier da Costa}

Graduado no curso de Produção Multimídia pelo

Centro Universitário Jorge Amado (Unijorge)

luciobouvier@hotmail.com

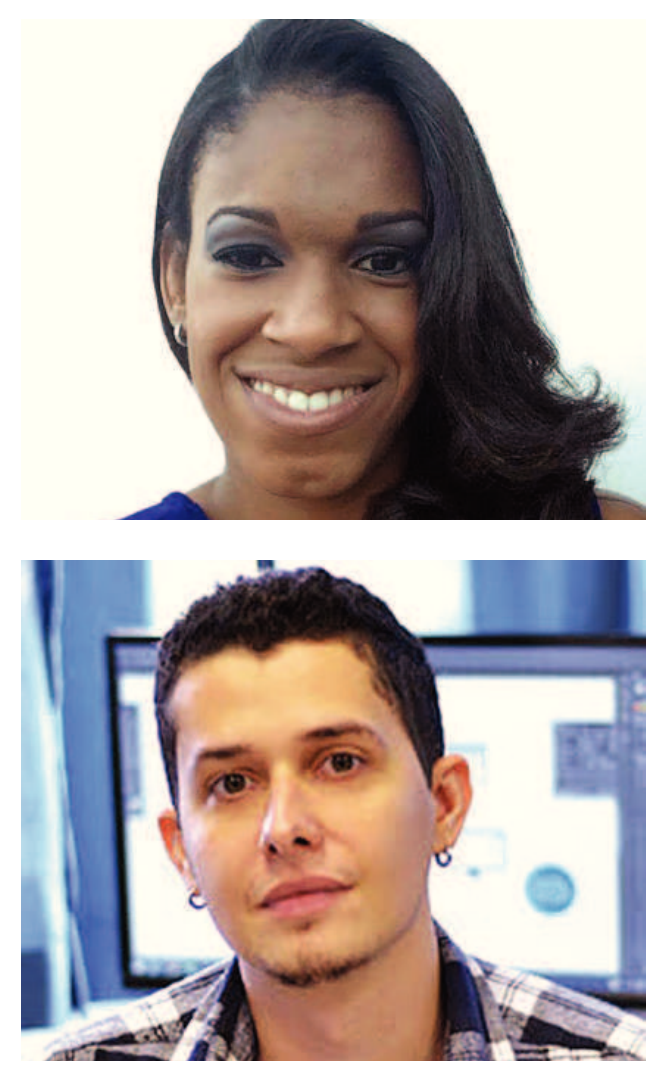

\section{Milca Bomfim Conceição}

Graduada no curso de Produção Multimídia pelo

Centro Universitário Jorge Amado (Unijorge)

milkinhafotografia@gmail.com

\section{Uilson de Freitas Fernandes}

Graduado no curso de Produção Multimídia pelo

Centro Universitário Jorge Amado (Unijorge)

uilsonfreitas@live.com

\section{RESUMO}

A divulgação de informações sobre o mosquito Aedes aegypti é uma das suas formas de combate e o site YouTube se mostra como uma ferramenta apropriada a esse propósito. Este artigo tem como objetivo propor um método simples de concepção de um vídeo/animação 3D, composto de duas partes, a modelagem conceitual e a modelagem digital, usando na primeira, uma síntese de autores de concepção de Roteiros, Design e Storyboard,e na última elementos modelados e animados em softwares 3D em uma ambiência totalmente digital. Os resultados permitiu a concepção em um processo rápido, mas completo, de produção audiovisual, desde a geração do seu conceito até o desenvolvimento no meio digital. 


\section{PALAVRAS-CHAVE}

Método. YouTube. Aedes aegypti.

\section{ABSTRACT}

The dissemination of information about the mosquito Aedes aegypti is one of the ways to combat it and the YouTube site shows as an alternative for this purpose. This article aims to propose a simple design method of a 3D video animation composed of two parts, the conceptual modeling and the digital modeling, the first part uses a synthesis of the authors in designing itineraries, Design and Storyboards, and last part uses elements modeled and animated in $3 \mathrm{D}$ software in a fully digital ambience. The results allowed the design in a quick but thorough process, audiovisual production, from the concept generation to the development in digital media.

\section{KEYWORDS}

Method. YouTube. Aedes aegypti.

\section{INTRODUÇÃO}

O alastramento nos últimos anos de doenças transmitidas por mosquitos como a malária, a dengue e, recentemente, a chikungunya dentre outras, mostra a notória fragilidade do povo brasileiro diante desses infortúnios. Tais doenças tropicais que ocorrem em vários países assolam, de forma aguda, muitas cidades brasileiras em certas épocas do ano e, de forma crônica, muitas regiões do Brasil, quase todo ano. Muitas delas são perigosas e algumas são letais. Ultimamente, duas delas têm tomado a atenção e a preocupação da população, a dengue e a chikungunya, por compartilharem o mesmo vetor transmissor, o mosquito Aedes aegypti, atitude reforçada pelo fato de não haver formas de cura à base de medicamentos que impeçam a contaminação. Esse combate, porém, apresenta-se como uma tarefa hercúlea. Apesar de envolver esforços das administrações públicas oficiais no combate ao mosquito mediante a ação de agentes especificamente treinados e equipados, sua eficácia tem se revelado reduzida, visto que é no interior dos lares que se contextualiza o principal problema: a falta de informação ou conscientização popular a respeito da doença e das suas formas de transmissão, o que agrava a baixa eficiência do combate ao mosquito, com a conseqüente ampliação das fronteiras da contaminação.

Por outro lado é notória também a relevância das redes sociais no papel de transmissão de informações de conteúdo diversificado. Redes sociais como o YouTube ${ }^{\circledast}$ podem ser tidas como referenciais no desempenho deste papel, alcançando milhões de usuários diariamente. E esse fato mostra ser oportuno para a comunicação de informações de cunho social, tal como aquelas sobre a ação do referido mosquito. Mas a produção de vídeos e/ou vinhetas educativas, que é comum nessa mídia, não é do domínio de muitos designers não especializados em produção multimídia e, além disso, são raros os métodos de concepção e produção de vídeos, mesmo os mais simplificados.

O objetivo deste artigo, então, é propor um método simplificado para a concepção e produção de um vídeo de animação $3 \mathrm{D}$, usando como objeto uma campanha de combate ao mosquito Aedes aegypti a ser publicado no YouTube ${ }^{\circledast}$. Este trabalho se justifica tanto por mostrar os passos metodológicos para a concepção e desenvolvimento de vídoes e/ou vinhetas animadas, quanto por oferecer informações sobre o combate à proliferação do mosquito. 


\section{O YOUTUBE ${ }^{\circledast}$ COMO VEÍCULO DE COMBATE AO MOSQUITO}

O YouTube é um website destinado à publicação, ao compartilhamento, à critica e comentários ou, simplesmente, à visualização de vídeos originais, que são feitos pelos próprios usuários. É uma rede social dentre as mais acessadas, um espaço comum de interesses diversos, com milhares de visitas diárias (SANTOS E LOPES, 2013). O termo vem do Inglês "you" que significa "você" e "tube" que significa "tubo" ou "canal", mas é usado na gíria para designar "televisão". Portanto, o significado do termo "youtube" poderia ser "você transmite" ou "canal feito por você". [...] No YouTube, os vídeos estão disponíveis para qualquer pessoa que queira assistir, bem como é possível adicionar comentários sobre os mesmos. (SIGNIFICADOS.COM.BR, 2014)

Dentre os muitos tipos de vídeos disponibilizados pelo YouTube estão os voltados para a instrução e/ou educação na forma de tutoriais, documentários vídeo-aulas e vídeos educativos/informacionais dos mais diversos assuntos. Para Dallacosta (2004) e Oliveira (2013) o uso de vídeos disponibilizados pelo YouTube está se tornando uma boa alternativa como ferramenta educacional, propiciando novas perspectivas para a educação. Além de oferecer os conteúdos informacionais, oferece também a possibilidade da interação entre os usuários tanto com os criadores do vídeo, quanto com os demais usuários, oferecendo também a possibilidade de acessar textos explicativos e links para outras páginas de informação, criando canais de comunicação e de informação, além dos métodos usuais.

Um dos assuntos que tem gerado a produção de vídeos do You Tube é o combate contra o mosquito Aedes aegypti . A OMS (Organização Mundial da Saúde) considera tanto a dengue quanto a chikungunya como dois dos mais importantes problemas de saúde pública dos últimos anos (WHO, 2012, PAHO/WHO, 2014), não somente no Brasil, mas em vários países. Somente a dengue pode infectar mais de 390 milhões de pessoas por ano, não somente nos países pobres, mas também nos desenvolvidos (MOREIRA, 2014) pondo em risco de infecção cerca de $40 \%$ da população mundial (VICENTE, 2014). Seu principal agente transmissor, o mosquito da dengue, o Aedes aegypti, é originário da África, provavelmente da Etiópia, onde a população selvagem "adquiriu grande capacidade de adaptação ao domicílio humano, acompanhando os povos em suas migrações pelos continentes" (BARRETO-NETO e COMETTI, 2007). Reproduz-se em águas limpas, em locais bem próximas às concentrações de habitações humanas, sendo, portanto, um fenômeno essencialmente urbano. Segundo Mendonça, Souza e Dutra (2009) o vetor tem grande proliferação no verão em decorrência das excelentes condições climáticas para a sua vida e reprodução.

A melhor maneira de combater a dengue ou a chikungunya é evitar a proliferação do mosquito. $O$ espaço doméstico, local de maior incidência de sua ocorrência, ao mesmo tempo em que oferece pouca autonomia aos agentes da saúde pública (CAZOLA et al 2011), também revela a grande desinformação dos moradores a respeito do problema. Para Cazola et al (2011), Dias et al (2010), portanto, não somente devem-se concentrar os esforços no combate direto ao mosquito, mas também na divulgação de informações que promovam o esclarecimento e mudança de hábitos e comportamentos que possam ser realmente efetivos no combate e diminuição do agente transmissor.

No esforço de aumentar o esclarecimento sobre o assunto, somam-se os numerosos vídeos voltados para o combate ao Aedes aegypti, em particular aqueles voltados à dengue. Como exemplo pode-se citar Lima (2010), que apresentou o vídeo "Cuidado com a Dengue", uma animação 2D com pouco mais de 1 minuto, que satiriza os comerciais do governo sobre o combate à dengue. Já o Vídeo "A Dengue em Nossa História" foi preparado pela prefeitura de Recife e por alunos de design da UFPE (PERNAMBUCO, 2011), como um curta-metragem, que esclarece 
de forma simples e direta o processo de chegada e desenvolvimento da doença na capital pernambucana e restante do País a partir de 1685 , data do primeiro registro em território nacional. Trabalho similar foi apresentado pela Prefeitura de Niterói (RIO DE JANEIRO, 2009), que concebeu um herói na forma de um agente mirim, que ensina a combater o mosquito. Como exemplo estrangeiro, pode ser destacada a "Campaña nacional contra el dengue" concebido pelo sindicato argentino de docentes privados SADOP (2010) e destinado ao publico infantil. A figura 1 mostra telas capturadas destes trabalhos.

Figura 1 - Exemplos de animações similares, disponibilizadas no YouTube

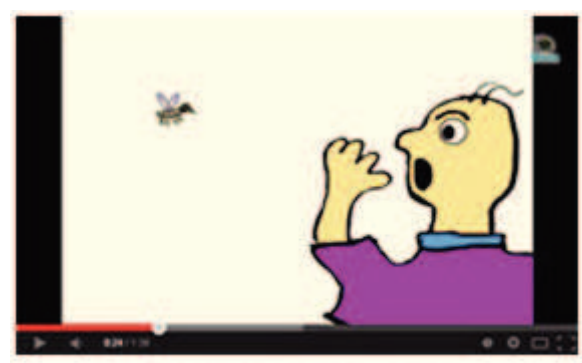

Cuidado com a dengue

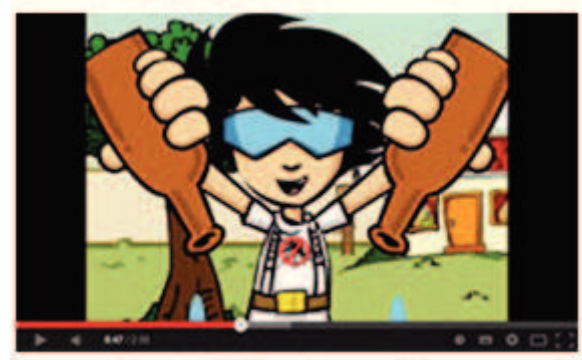

Agente mirim contra a dengue

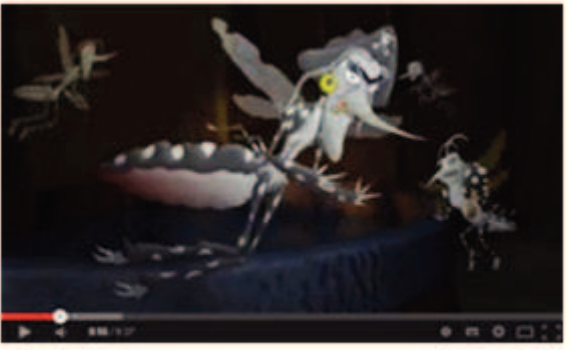

A dengue em nossa história

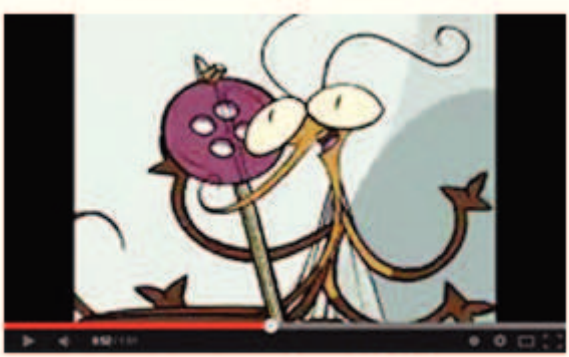

Campaña nacional contra el dengue

Fonte: Lima (2010), Pernambuco (2011), Rio de Janeiro (2009) e SADOP (2010)

Esses vídeos representam o esforço para o esclarecimento da população sobre a dengue. Possuem linguagem acessível e de fácil compreensão, principalmente para o publico infantil e jovem. Entretanto foi observado que são longos, indo de um minuto a dezenas de minutos e, apesar de serem fáceis de acessar no YouTube como produto final, são inviáveis em campanhas informacionais, disponibilizadas junto a outros vídeos na mesma mídia. Um vídeo mais curto, de poucas dezenas de segundos, como o proposto neste projeto, pode ser uma solução mais adequada.

\section{PROJETO DA ANIMAÇÃO}

Para a concepção da animação foi previsto um método composto por 2 etapas (figura 2):

- MODELAGEM CONCEITUAL: Etapa para a concepção da estória e criação dos elementos da animação. Reúne a argumentação, a concepção do personagem, o desenvolvimento do roteiro e o desenho do Storyboard.

- MODELAGEM DIGITAL: Etapa de desenvolvimento e produção da animação com ferramentas digitais. Reúne a descrição do software, o desenvolvimento do personagem, o desenvolvimento da animação e dos cenários e a montagem final. 
Figura 2 - Esquema da proposta metodológica

\begin{tabular}{l|l|l|}
\hline \multicolumn{2}{|l|}{ MODELAGEM CONCEITUAL } & \multicolumn{1}{c|}{ MODELAGEM DIGITAL } \\
\hline 1. ANÁLISE DE SIMILARES & 1. & MODELAGEM DO PERSONAGEM \\
2. ARGUMENTO & 2. MODELAGEM DO CENÁRIO E ANIMAÇÃO \\
3. CONCEPÇÃO DO PERSONAGEM & 3. MONTAGEM FINAL \\
4. ROTEIRO & & \\
5. STORYBOARD & & \\
\hline
\end{tabular}

Fonte: construção dos autores

\subsection{MODELAGEM CONCEITUAL}

\subsubsection{ANÁLISE DE SIMILARES}

A análise de similares constitui a primeira etapa do projeto. Nela buscou-se levantar algumas ideias e características das animações acessadas no YouTube, referenciadas na Figura 1. Segundo Padovani, Spinillo e Gomes (2009) a análise de similares traz informações importantes sobre tendências e ideias de soluções, identificação de procedimentos conceituais e técnicos, além de apontar características tanto desejáveis quanto falhas, que podem orientar um projeto de design. Desta forma realizou-se uma análise conceitual, na forma de comentários descritivos de três dos vídeos pesquisados, vistos no quadro 1.

Quadro 1 - Análise de similares

$$
\text { SIMILAR }
$$
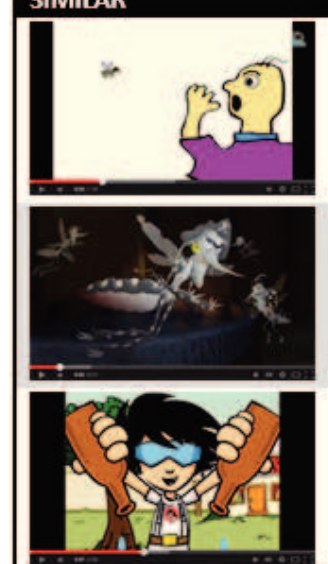

\section{DESCRIÇÃO / ANÁUSE}

Cuidado com a dengue. Animação de 1 minuto e meio aproximadamente, desenvolvida com traço estilo infantil. É contextualizada em ambiente domiciliar, com formato misturando drama e comédia. Seus personagens são duas pessoas envoltas com um mosquito, que insiste em driblar todas as tentativas de eliminá-lo. Quase no final, surge uma mensagem de texto: "Dengue: um caso de saúde pública".

A dengue em nossa história. Com aproximadamente 9 minutos, essa animação em 3D acrescenta uma narrativa verbal e fotográfica à animação para historiar a chegada do mosquito ao Brasil. Mescla personagens animados e partes de vídeos reais. Usa diálogos estilo musical como diferencial. Nessa animação são acrescentadas, também, as formas de proliferação, de combate ao mosquito e os cuidados com quem já apresenta a doença.

Agente mirim contra a dengue. Com exatos 2 minutos, essa animação $2 D$ usa o estilo super-herói, com traço simples, lembrando vagamente o mangá japonês e usando bastante cores. Usando um personagem mirim, traz a explicação sobre o combate ao mosquito através de texto verbal junto a um formato tipo ação. Seu publico é o infantil, passando a ideia do envolvimento de crianças na prevenção da proliferação do mosquito.

Fonte: construção dos autores

Em síntese, são animações voltadas para o público Infanto-juvenil, com características de traço simples. Usam uma narrativa que mistura informações verbais, textuais e visuais para transmitir o conteúdo. Observou-se que o uso de um roteiro rápido, com no máximo 1 a 2 minutos é mais confortável e não menos eficiente do que aquele que usa um tempo maior. Essas ideias são o ponto de partida da concepção da animação proposta.

\subsubsection{ARGUMENTAÇÃO}

Esta fase foi baseada e adaptada a partir da sugestão de concepção e produção de vídeos da TvEscola (BRASIL, 2014). É o registro da inspiração e da idéia inicial do vídeo. Primeiramente é definido o tema e a partir deste, o recorte e a sinopse. Em seguida são definidas a justificativa ou relevância e a mensagem que se quer passar. Depois é definido o público alvo, item fundamental para a escolha do tipo de linguagem visual e verbal a ser adotada. Em seguida é definido o formato do roteiro a ser adotado, podendo ser educativo, ficção, comédia, drama, terror, documentário, aventura, ação, crime ou guerra, dentre outros. E por último, a 
sinopse da animação: a ideia apresentada na forma de uma síntese. A tabela 1 mostra a concepção da argumentação deste projeto.

Tabela 1 - Concepção da argumentação

\begin{tabular}{ll} 
ETAPA & DESCRIÇÃO \\
\hline Tema & Dengue \\
Recorte & O combate ao mosquito Aedes aegypti \\
Ambiente & Contextualizado em uma área urbana \\
Justificativa & A necessidade de divulgar informações de esclarecimento sobre o problema \\
Mensagem & Devemos conhecer os hábitos do mosquito para combatê-lo \\
Público alvo & Infanto-juvenil \\
Formato & Educativo com traços de drama e de comédia \\
Sinopse & Com o título de "lixão", um vídeo de 15 segundos irá sugerir que deve haver mais \\
& rigor no combate ao mosquito da dengue. O personagem principal será um vilão \\
& representando o mosquito, que vive num lixão sem ser incomodado até ser \\
& encontrado e eliminado de surpresa. As cenas devem retratar sua personalidade do \\
& tipo "bom vivant" e a cena da eliminação deverá ser representada por uma tela \\
& preta, trazendo um pouco de suspense e drama, com o texto da campanha \\
& antimosquito.
\end{tabular}

Fonte: construção dos autores

Essa argumentação busca satisfazer o objetivo da animação: informar sobre a importância do combate ao mosquito. Para isso seu detalhamento cobriu conceitos básicos, que permitem uma concepção de uma animação 3D simples, mas eficiente, necessária para que seu conteúdo seja transmitido no tempo estipulado de 15 segundos.

\subsubsection{CONCEPÇÃO DO PERSONAGEM}

O personagem é o ponto central de uma trama, elemento fundamental para envolver o público com a idéia que se propõe comunicar. Pode ser considerado como a representação de algo ou alguém, inspirado na realidade ou concebido na ficção, capaz de sustentar a narrativa de uma obra proposta nas várias mídias, tal como no vídeo, no teatro ou na literatura, por exemplo. Podem exercer papel de protagonista, antagonista ou papeis secundários, ou coadjuvantes, no contexto da trama.

A literatura estudada apresenta alguns métodos de criação de personagens, como os propostos por Field (2001), Fadel (2010), Souza (2011), Francisco e Garone (2013) e Ekström (2013), que foram usados para a construção do método proposto e aplicado neste projeto. Assim, para a criação de um personagem foram estudados alguns aspectos destinados a caracterizá-lo e defini-lo. Depois foram atribuídas as características de subjetividade: os traços de personalidade e comportamentais. Essas características foram importantes para a determinação da postura corporal do personagem. O planejamento do personagem está representado na Tabela 2.

Tabela 2 - Planejamento conceitual do personagem

\begin{tabular}{ll} 
CARACTERÍSTICAS & DESCRIÇÃO \\
\hline Modelo inspirador & Mosquito da dengue \\
Tipo & Vilão \\
Personalidade & Provocativo, oportunista, "bom vivant" \\
Comportamentais & Despojado, relaxado, agressivo. \\
Físicas & Próximas ao mosquito, mas com elementos humanos \\
Nome & Ed, o egípcio.
\end{tabular}

Fonte: construção dos autores 
Primeiramente foi estudado o modelo de inspiração, o ponto de partida da concepção do personagem, neste caso o mosquito da dengue. Para isso foi planejado um moodboard, ou painel de inspiração, mostrado na figura 3 , que segundo Pereira (2010) é uma ferramenta visual na sua essência, usando colagens de imagens selecionadas dentro do contexto pesquisado e que busca auxiliar no surgimento de insights criativos. Serve, principalmente, como base de referência e de inspiração para ideias, formas, texturas, cores. O moodboard foi desenvolvido com a colagem digital de fotografias e desenhos do mosquito, baixados através da ferramenta de buscas Google imagens. Foram observados o formato (shape), volumes e proporções do corpo, cores e padronagens superficiais.

Figura 3 - Moodboard do mosquito - modelo de inspiração

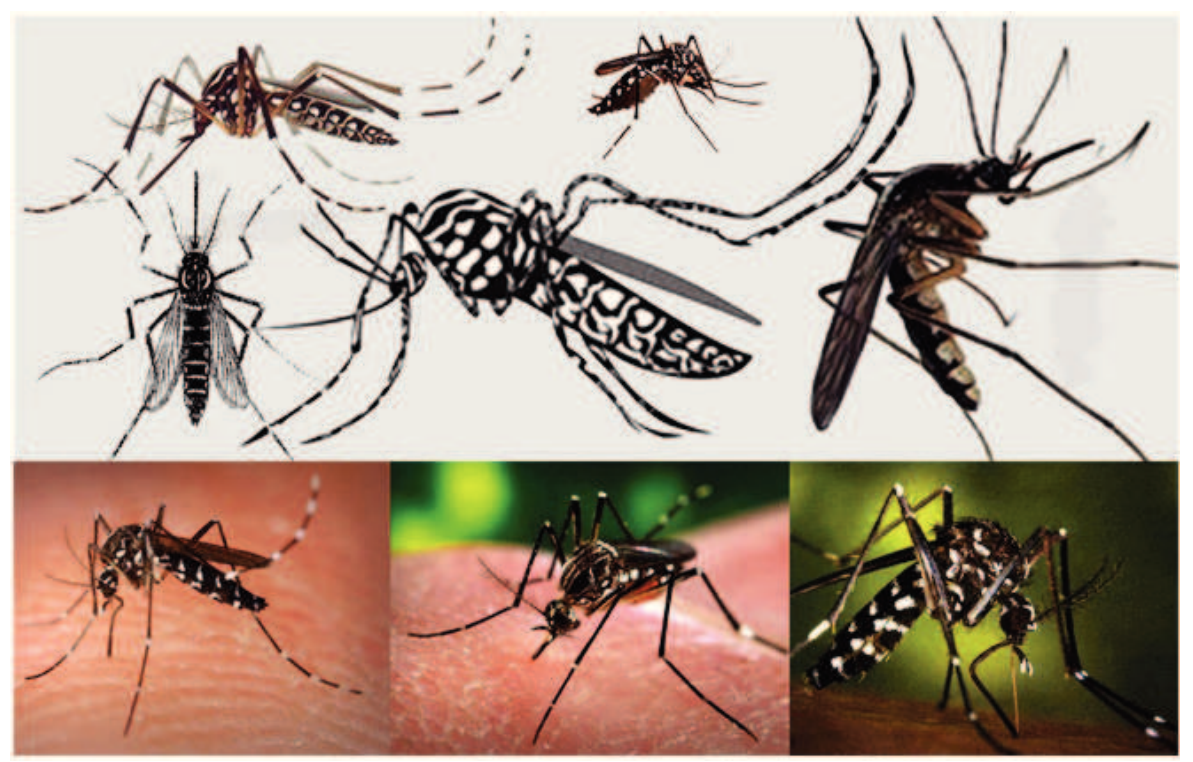

Fonte: construção dos autores a partir de imagens obtidas com o Google imagens

Após esses estudos iniciais, foi realizado o estudo de desenho que determinou o personagem enquanto representação gráfica. Neste caso a equipe usou desenho artístico manual, na forma de rascunhos e sketches a lápis preto.

Figura 3 - Moodboard do mosquito - modelo de inspiração
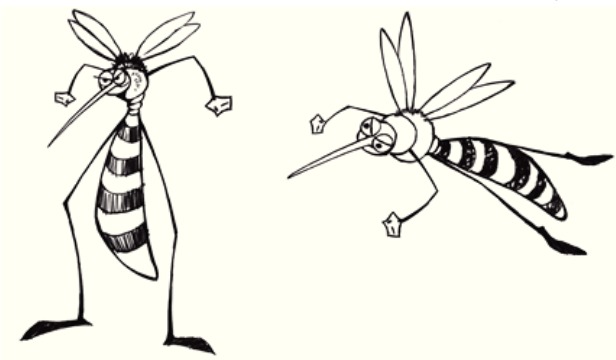

Fonte: construção dos autores
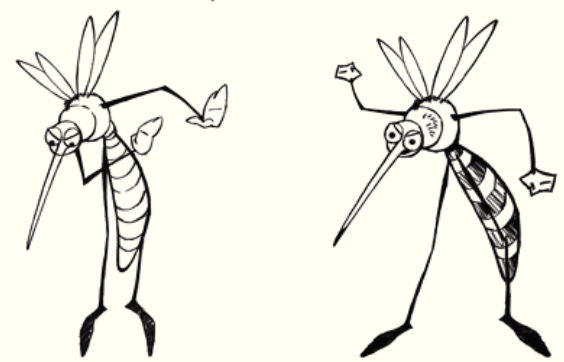
Apelidado de "Ed, o egípcio", Figura 4, o personagem único da ação será uma recriação digital através de softwares e em estilo cartoon 3D do Mosquito Aedes aegypti. O personagem é um vilão de caráter "provocativo", "oportunista" mas "bom vivant", conferindo-lhe assim um perfil metafórico de um ser humano que se aproveita indevidamente de situações em benefício próprio, no caso, proveito de lugares calmos e favoráveis para se reproduzir.

\subsubsection{ROTEIRO}

Segundo Field (2001) o roteiro é a estória contada através de imagens, desenhos, textos de diálogos, narrações e descrições, podendo seguir uma ordem cronológica, dentro do contexto da trama. Baseado em Comparato (1995), foram sugeridos dois critérios para estruturação do roteiro: a idéia da trama do vídeo, fruto da imaginação criativa dos seus autores, baseada nas informações organizadas no argumento; e o conflito da trama, elemento que envolve o personagem com a idéia na forma de antagonismos e contradições com a mesma. Estes critérios são mostrados na tabela 3.

Tabela 3 - Critérios estruturantes do roteiro

\section{CRITÉRIOS DESCRIÇÃO}

Ideia O mosquito Ed, descansando na sua casa num lixão urbano, é surpreendido por alguma ação de limpeza feita de surpresa e desaparece em seguida (sugestão de eliminação). Do ponto de vista do personagem, não deve ficar bem claro o que acontece fora do seu abrigo, dando uma ideia de eliminação de surpresa.

Conflito $\mathrm{O}$ conflito vivido por Ed entre sentimento de boa vida com a condição de vilão pelos seres que dão condição de vida, ao mesmo tempo em que querem elimina-lo.

Fonte: construção dos autores

O roteiro foi então desenvolvido a partir de uma etapa de brainstorming, uma tempestade de ideias livre, que envolveu toda a equipe do projeto da animação. Sua definição se realizou através de uma síntese das melhores ideias de cada membro. Alguns critérios foram, entretanto, respeitados:

a) Ter a argumentação como guia, procurando sempre segui-la e evitando novas propostas;

b) Usar uma linguagem majoritariamente visual, minimizando conteúdo textual ou verbal;

c) Respeitar o tempo estipulado de 15 segundos, evitando um roteiro com muitas etapas;

$O$ roteiro foi assim desenvolvido em seis cenas. A tabela 4 mostra a descrição das cenas. A partir dessas descrições, foi elaborada a etapa seguinte: o Storyboard.

Tabela 4 - Descrição das cenas do roteiro

\section{CENA DESCRIÇÃO}

1 Visualização de uma lata velha, localizada em terreno baldio ou

1 lixão, num bairro de uma grande cidade;

2 Dentro dessa lata vive confortavelmente um mosquito da dengue: Ed, o egípcio; música suave e agradável sugerindo tranquilidade;

3 Ele nota algo que interrompe seu descanso;

4 Faz-se uma sombra que cresce, aumentando a tensão de Ed. A sombra aumenta indicando que algo perigoso se aproxima.... Vê-

5 se a tela escura e somente os olhos assustados do mosquito ... Ed é eliminado

6 Entra cartela animada da campanha com um carimbo sonoro: "não dê boa vida ao mosquito Aedes aegypti, faça sua parte"
TEXTO / SOM

Melodia suave, indicando tranquilidade;

Ídem;

Música que sugere suspense, barulho metálico se aproximando;

ídem, som mais alto;

Barulho metálico, batida tipo marreta, som alto:

Texto escrito e falado, sem música.

Fonte: construção dos autores 


\subsubsection{STORYBOARD}

O storyboard pode ser considerado a representação gráfica do roteiro, uma técnica usada para mostrar um conceito de ação numa seqüência lógica de desenhos (POWELL e MONAHAN 1987, p. 68). Através do desenho, são definidas posições, tomadas, detalhes do cenário, expressões, sentimentos e movimento dos personagens, além de muitas outras idéias contidas no roteiro, principalmente aquelas difíceis de serem descritas por palavras. Torna-se, portanto, um guia imagético para a realização das cenas da animação. A figura 5 mostra o Storyboard da animação em projeto, desenhado como rascunhos a lápis. Foi desenhada uma parte relativa a cada cena proposta pelo roteiro, sempre com a preocupação de preencher o tempo máximo estipulado.

Figura 5 - Storyboard
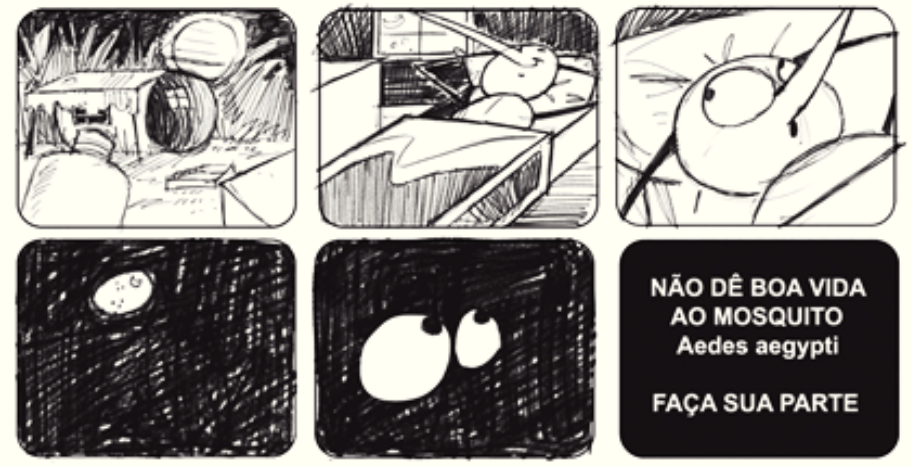

NÃO DÊ BOA VIDA AO MOSQUITO

Aedes aegypti

FAÇA SUA PARTE

Fonte: construção dos autores

\subsection{MODELAGEM DIGITAL}

\subsubsection{DESCRIÇÃO DOS SOFTWARES USADOS NA ANIMAÇÃO}

A modelagem 3D é uma área da computação gráfica que apresenta ferramentas na forma de softwares destinadas ao projeto nas áreas de design, cinema, arquitetura e engenharia, dentre outros. Entre estas se destacam o Maya, o 3DS Max, o Cinema 4D ou o Blender, sendo este ultimo, gratuito. Estas ferramentas, antes restritas às empresas especializadas e a indústrias, se tornaram acessíveis com o advento da computação pessoal, embora necessitem de conhecimento e treinamento para opera-las (NETO e MELO, 2005). Desta forma, usando como critério a facilidade de manipulação, foram selecionadas duas destas ferramentas para o desenvolvimento da animação aqui proposta: o ZBrush e o 3DS Max. Embora pudessem ser usados separadamente, foi percebido o interesse da equipe em estudar a integração de softwares distintos.

O ZBrush, da Pixologic, é um software de modelagem e escultura tridimensional usado em filmes e animações e também utilizado por desenvolvedores de games 3D, combinando modelagem, texturização e pintura. Segundo seu fabricante (PIXOLOGIC, 2014), este softwareéconhecido por sua simplicidade e pode ser usado por leigos, oferecendo bons resultados. Sua principal característica produtiva é que seu uso é análogo à maneira de se fazer uma escultura real, podendo criar modelos digitais de alta resolução (até dez milhões de polígonos) para uso em filmes, jogos e animações. Atualmente o ZBrush custa cerca de U\$700,00, mas possui um similar gratuito, desenvolvido pelo mesmo fabricante, denominado Sculptris, que possui ferramentas básicas, porem essenciais, destinadas quase exclusivamente para o designer leigo em desenho, modelagem e animação 3D, tornando-se útil como treinamento e familiarização com esse tipo de programa.

Já o 3DS Max, de acordo com seu fabricante, a Autodesk (2014), é um tradicional 
programa de modelagem 3D profissional e voltado para o desenho, modelagem e renderização de imagens e animações, usado em produção de filmes de animação, criação de personagens de jogos em 3D, vinhetas e comerciais para TV, maquetes eletrônicas, incluindo a criação de ambientes virtuais. A renderização pode ser feita em apenas um frame (tela estática), quando utilizada para fazer uma imagem 3D igualmente estática. Suas ferramentas, embora possuam grau moderado de complexidade, permitem a geração de renderizações de alta qualidade, com as quais são geradas imagens fotorrealísticas, simulando vários tipos de ambientes e cenários internos e externos, além dos personagens. O 3DS Max é um software caro, mas também tem um similar gratuito e de código aberto, o Blender3D, desenvolvido pela Blender Foundation, que possui ferramentas não menos complexas e poderosas, exigindo um certo treinamento preliminar.

\subsubsection{MODELAGEM DO PERSONAGEM}

Nessa etapa o personagem foi modelado no Zbrush a partir da etapa de concepção de personagem. O personagem foi esculpido a partir de formas básicas como polígonos ou esferas. O processo é similar à modelagem com massa plástica infantil, porém em um ambiente digital. A Figura 6 mostra esse processo.

Figura 6 - Etapas da modelagem do personagem usando o software ZBrush
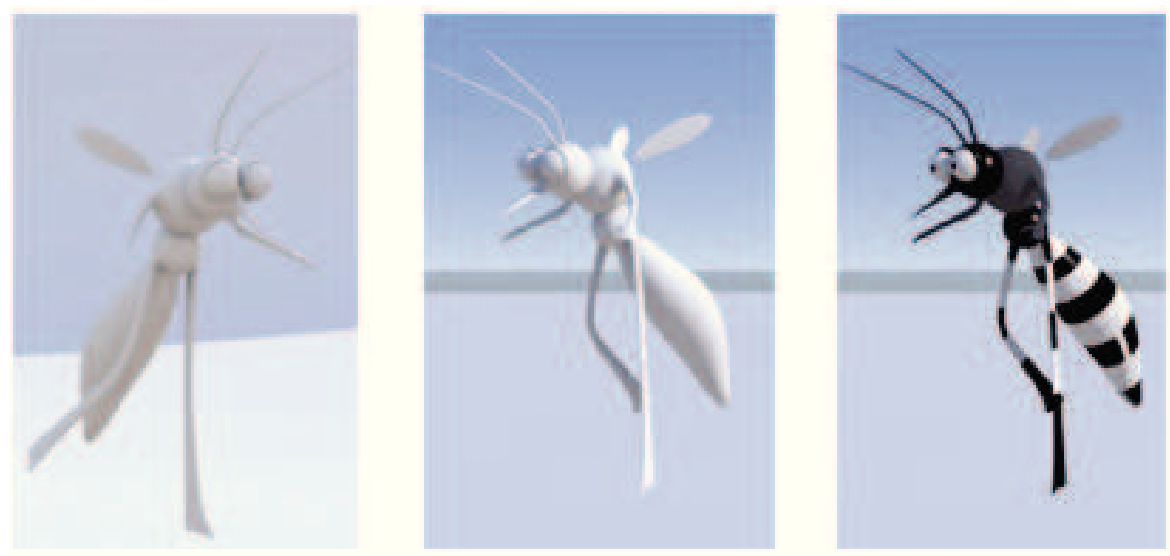

Fonte: construção dos autores

Com o personagem devidamente modelado, foi aplicado o processo de "rig" ou "rigging", que permitiu que o mesmo fosse animado. O "rig" consiste em introduzir um esqueleto no personagem que depois será associado a sua malha no processo conhecido por "skinning" que unirá esse esqueleto à malha que funciona como a "pele" do personagem. Toda a plástica do personagem e dos seus movimentos dependem da habilidade da equipe animadora e do conceito da trama.

\subsubsection{MODELAGEM DOS CENÁRIOS E DA ANIMAÇÃO}

Após a conclusão da modelagem do personagem, o cenário foi construído no 3DS Max seguindo o mesmo processo de observação usado anteriormente, tendo como referência objetos reais como latas de óleo, garrafas pet e caixas de fósforo, além de alguns objetos de bibliotecas digitais. O desenvolvimento da animação do cenário em 3D dividiu-se em três etapas: modelagem, animação e renderização. Alguns detalhes como janelas e texturas de adereços de casa foram utilizados para simular a casa do mosquito. As ferramentas e comandos usados para a modelagem foram as considerados comuns, com calibração default, incluindo as bibliotecas de texturas e materiais. A modelagem partiu do uso de volumes sólidos os quais foram "esculpidos" através de cortes, manipulação de edges e vértices, solda de objetos, usando principalmente visualizações em wirefrmes, sempre se baseando nos objetos de referencia. 
Só então o personagem e o cenário foram unidos para iniciar o processo de animação de movimentos do personagem, movimento de câmeras, inserção da trilha sonora. Para isso, o mosquito modelado no Zbrush foi salvo e em seguida importado como um objeto para dentro do 3D Max. O render foi o processo final, onde todas as cenas de animação em frames foram transformadas em vídeo. Para isso foi necessário ajustar a iluminação digital da cena e trabalhar as texturas e materiais que compõem os cenários e personagens. A figura 7 mostra algumas imagens capturadas do processo final da produção da animação.

Figura 7 - Algumas imagens do processo de renderização e finalização da animação

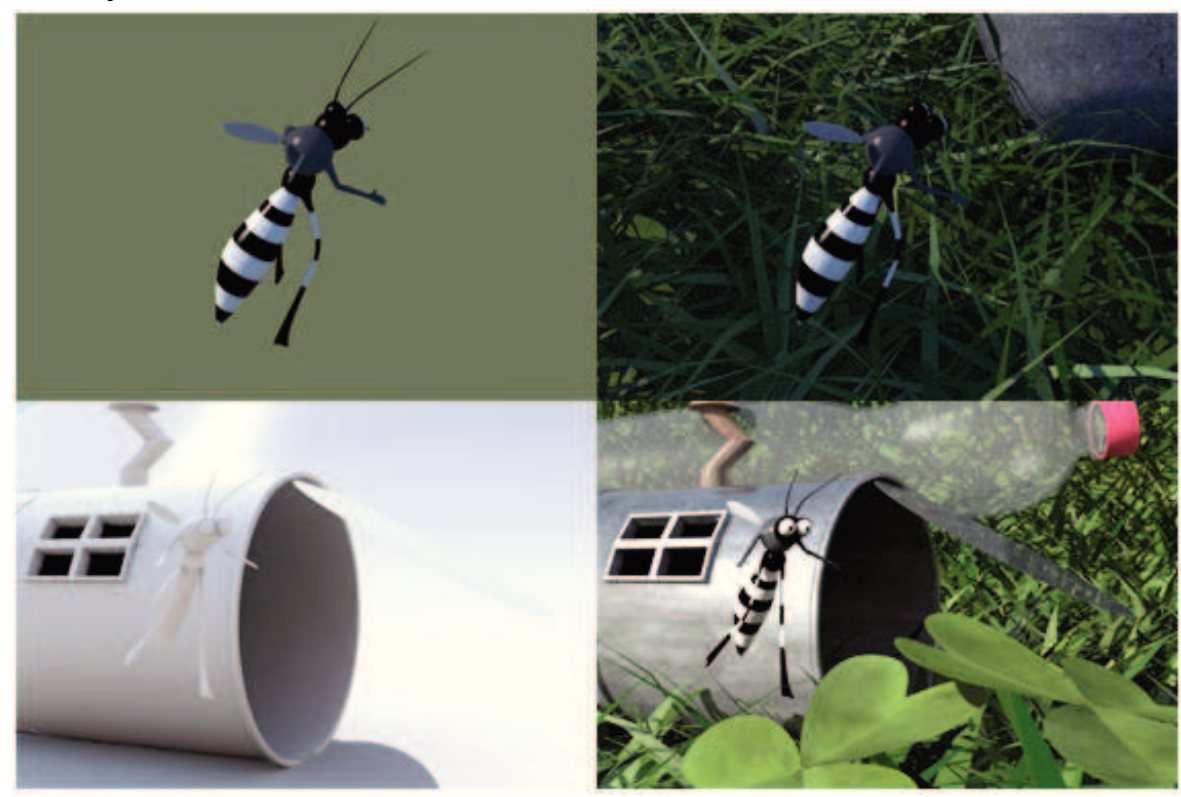

Fonte: construção dos autores

\section{CONSIDERAÇÕES FINAIS}

Nesse artigo foi delineado um estudo interdisciplinar relacionando a temática de responsabilidade social, com a metodologia do design de vídeo e técnicas de animação 3D, relacionando parte dos conteúdos de algumas disciplinas do curso de Produção Multimídia, de forma transversal. Este vídeo, de apenas 15 segundos, foi então produzido com os requisitos mínimos para ser publicado no YouTube.

Os resultados encontrados nesse trabalho permitiram a investida em um processo completo de produção audiovisual, no segmento de animação. Foram desenvolvidas todas as fases de concepção e desenvolvimento, desde a argumentação e o rascunho do personagem, passando pelo roteiro e storyboard da peça, produção da modelagem digital de personagem, cenários e edição de áudio e a finalização, renderização e comercialização do produto final, usando alguns dos softwares do mercado profissional.

\section{REFERÊNCIAS}

AUTODESK. 3DS Max. 2014. Disponível em http://www.autodesk.com/ education/free-software/3ds-max Acesso em 25/10/2014

BARRETO-NETO, Aurélio Azevedo. COMETTI, Rafaela Recla. Sensoriamento remoto como ferramenta auxiliar no combate à ocorrência de dengue na cidade de Vitória-ES. Anais XIII Simpósio Brasileiro de Sensoriamento Remoto. Florianópolis, 2007, INPE, p. 3733-3738. Disponível em http://marte.sid.inpe.br/col/ dpi.inpe.br/sbsr@80/2006/11.15.15.19.59/doc/3733-3738.pdf Acesso em 12/09 2014 
BRASIL. Ministério da Educação. Oficina de produção de vídeos. Curta Histórias. 2014. Disponível em http://curtahistorias.mec.gov.br/images/pdf/dicas_ producao_videos.pdf Acesso em 12/09 2014

CAZOLA, Luiza Helena de Oliveira et al. O Controle da Dengue em duas Áreas Urbanas do Brasil Central: percepção dos moradores. Saúde Social. São Paulo, v.20, n.3, p.786-796, 2011. Disponível em http://www.scielo.br/scielo.php?pid=S010412902011000300021\&script=sci_arttext Acesso em 14/09 2014

COMPARATO, Doc. Da criação ao roteiro. Rio de Janeiro. Rocco. 1995

DALLACOSTA, Adriana. Possibilidades educacionais do uso de vídeos anotados no Youtube. Departamento de Educação e Cultura do Exército Brasileiro. 2004. Disponível em http://www.ensino.eb.br/portaledu/conteudo/ artigo9513.pdf Acesso em 12/09 2014

DIAS, Larissa B. A. Dengue: transmissão, aspectos clínicos, diagnóstico e tratamento. Medicina (Ribeirão Preto) 2010; 43(2): 143-52. Disponível em http:// revista.fmrp.usp.br/2010/vol43n2/Simp6_Dengue.pdf Acesso em 12/09 2014

EKSTRÖM, Hanna. How Can a Character's Personality be Conveyed Visually, through Shape. Degree Project in Game Design. Suécia, 2013. Disponível em http://www.diva-portal.org/smash/get/diva2:637902/FULLTEXT01.pdf Acesso em 15/09 2014

FADEL, Luciane Maria. Design de personagem: Um enfoque na qualidade da experiência. Anais do $9^{\circ}$ Congresso Brasileiro de Pesquisa e Desenvolvimento em Design. Universidade Anhembi Morumbi. São Paulo. 2010. Disponível em http://blogs.anhembi.br/congressodesign/anais/design-de-personagem-umenfoque-na-qualidade-da-experiencia/ Acesso em 23/09 2014

FIELD, Syd. Manual do roteiro. Os Fundamentos do Texto Cinematográfico. Rio de Janeiro. Editora Objetiva Ltda. 2001

FRANCISCO, Thiago. GARONE, Priscilla Maria Cardoso. Design de personagens e representação gráfica: uma construção semiótica. Anais do Graphica 2013. UFSC. Santa Catarina. 2013. Disponível em http://wright.ava.ufsc.br/ grupohipermidia/ graphica2013/trabalhos/DESIGN\%20DE\%20PERSONAGENS\%20E\%20 REPRESENTACAO\%20GRAFICA\%20UMA\%20CONSTRUCAO\%20SEMIOTICA.pdf Acesso em 23/09 2014

LIMA, Vinícius. Cuidado com a dengue! ( animação ). UFPB. Campina Grande. 2010. Disponível em www.youtube.com/watch?v=etgAW_aF0MI Acesso em 23/09 2014

MENDONÇA, Francisco de Assis. SOUZA, Adilson Veiga e. DUTRA, Denecir de Almeida. Saúde pública, urbanização e dengue no Brasil. Sociedade \& Natureza. Uberlândia, 21 (3): 257-269. 2009. Disponível em http://www.scielo.br/ scielo.php?pid=S1982-45132009000300003\&script=sci_arttext Acesso em 23/09 2014

MOREIRA, Assis. OMS estima que dengue pode infectar 390 milhões por ano no mundo. Valor Econômico. 2014. Disponível em http://www.valor.com.br/ brasil/3505186/oms-estima-que-dengue-pode-infectar-390-milhoes-por-anono-mundo Acesso em 12/09 2014 
MELO, Andrei Krepsky de. NETO, Walter Dutra da Silveira. Técnicas de animação em ambientes 3D. Revista DAPesquisa. Vol. 1 No2. 2005. Disponível em http:// www.ceart.udesc.br/revista_dapesquisa/volume1/numero2/design.htm Acesso em 25/08 2015

OLIVEIRA, Débora Silva de. O uso do vídeo em EAD: desafios no processo de ensino aprendizagem. Revista Cesuca Virtual. V. 1, n. 1, 2013. Disponível em http://ojs.cesuca.edu.br/index.php/cesucavirtual/article/view/422 Acesso em $17 / 092014$.

PADOVANI, Stephania. SPINILLO, Carla Galvão. GOMES, Ítalo Mata de Araújo. Desenvolvimento e aplicação de modelo descritivo-normativo para análise de websites. Produção, v. 19, n. 3, 2009. Disponível em http://www.scielo.br/pdf/ prod/v19n3/09.pdf Acesso em 23/08/2015

PAHO/WHO. Pan American Health Organization/ World Health Organization. Chikungunya. 2014. Disponível em http://www.paho.org/hq/index. php?option=com_topics\&view=article\&id=343\&ltemid=40931 Acesso em 23/09/2014

PEREIRA. Taís Vieira. O moodboard como espaço para construção de metáforas. Universidade do Vale do Rio dos Sinos. Porto Alegre. 2010. Dissertação. Disponível em http://biblioteca.asav.org.br/vinculos/tede/TaisVieiraPereira.pdf Acesso em 23/08/2015

PERNAMBUCO. Prefeitura. A Dengue em nossa História. Recife. 2011. Disponível em https://www.youtube.com/watch?v=5dkpti5pkBo Acesso em 17/09 2014.

PIXOLOGIC. ZBrush Overview. 2014. Disponível em http://pixologic.com/ zbrush/features/overview/ Acessado em novembro de 2014

POWELL, Dick. MONAHAN, Patrícia. Advanced Marker Techniques. Londres. Macdonald Illustrated. 1987

RIO DE JANEIRO. Agente Mirim Contra a Dengue. Niterói. 2009. Disponível em https://www.youtube.com/watch?v=XZt33dVRp9U Acesso em 17/09 2014.

RUSSET, Robert; STARR, Cecile. Experimental animation: Origins of a new art. Newtons. Da Capo Press, 1988.

SADOP. Campaña nacional contra el dengue. 2010. Disponível em https:// www.youtube.com/watch?v=OopnVYJokFw Acesso em 17/09 2014.

SANTOS, Jaqueline Araújo dos. LOPES, Marcelo Dias. A utilização das redes sociais pelos universitários da cidade de Itajubá-MG. Anais do Encontro Científico Sul Mineiro de administração, contabilidade e economia. Itajubá, 2013. Disponível em http://www.facesm.br/userfiles/webfiles/Artigo\%209.pdf Acesso em 17/09 2014.

SIGNIFICADOS.COM.BR. Significado de Youtube. 2014. Disponível em http:// www.significados.com.br/youtube/ Acesso em 17/08 2014.

SOUZA, Francis Martins de. Design de Games. Material didático referente ao Workshop do Centenário. 2011. Disponível em http://unisalesianogames.files. wordpress.com/2011/08/59051645-design-de-games-material-didatico.pdf 
Acesso em 17/09 2014.

VICENTE, Rebeca. Dengue é risco para cerca de $40 \%$ da população mundial, estima OMS. Folha de São Paulo. Setembro de 2014. Disponível em http://www1. folha.uol.com.br/treinamentocienciaesaude/2014/06/1477781-dengue-e-riscopara-cerca-de-40-da-populacao-mundial-estima-oms.shtml Acesso em 17/09 2014.

WHO. World Health Organization. 2012-2020. Global strategy for dengue prevention and control. Geneva. 2012. Disponível em http://apps.who.int/iris/ bitstream/10665/75303/1/9789241504034_eng.pdf?ua=1 Acesso em 17/09 2014.

\section{Prof. Dr. Marcelo Geraldo Teixeira}

Designer (UNEB), professor de Design Gráfico e de Produto. Mestrado em Tecnologias Limpas e Doutorado em Eng. Industrial pela UFBA. Foi professor de design na Faculdade da Cidade (rede FTC) e da Unijorge. É atualmente professor de design na DeVry Brasil |Faculdade Ruy Barbosa e da UNEB.

Algumas publicações:

TEIXEIRA, M. G. ; CÉSAR, Sandro Fábio ; KIPERSTOK, Asher . Desenvolvimento de marca de identidade visual para uma comunidade quilombola: o caso de Giral Grande. Educação Gráfica (UNESP. Bauru), v. 15, p. 7-24, 2011.

TEIXEIRA, M. G. ; CÉSAR, Sandro Fábio ; KIPERSTOK, Asher . O artesanato de retalhos da comunidade quilombola de Giral Grande. Afro-Ásia (UFBA. Impresso), v. 44, p. 219-246, 2011.

TEIXEIRA, M. G. ; BARBOSA, Sarah ; ROSAS, Carine de F.C. ; BARRETO, Mariana B. P. . Fantasias de Carnaval, permanências e rupturas Estudo de caso - O Carnaval de Maragojipe. lara: Revista de Moda, Cultura e Arte, v. 3, p. 110-136, 2010.

TEIXEIRA, M. G. ; CÉSAR, Sandro Fábio . Ecologia Industrial e Eco-Design: Requisitos Para a Determinação de Materiais Ecologicamente Corretos. Revista Design em Foco (Salvador), Salvador, v. 2, n.1, p. 51-30, 2005.

TEIXEIRA, M. G. ; CÉSAR, Sandro Fábio . Design requirements to prevent pollution: using agro industrial residues in new products. In: 1ST Product and Service Design Symposium and Exhibition on Agricultural Industries: Olive Oil, Wine and Design, 2005, Izmir. 1ST Product and Service Design Symposium and Exhibition on Agricultural Industries: Olive Oil, Wine and Design, 2005.

\section{Amaury Moura de Aquino}

Publicitário, graduado no curso de Produção Multimídia pela Unijorge (BA), atua na áreas de produção gráfica e direção de arte para agências de propaganda. Salvador, Bahia, Brasil

\section{Larissa da Cruz Rosario}

Designer e fotógrafa, graduada no curso de Produção Multimídia pela Unijorge (BA), atua na área de tecnologia e impressão gráfica.

\section{Lucio Bouvier da Costa}

llustrador e designer, graduado em Produção Multimídia pela Unijorge (BA). Atua em trabalhos publicitários e editoriais como Diretor de Arte, Character Designer, Conceptual Artist, Digital painter, Modelador 3d, render 3d. Salvador, Bahia, Brasil.

\section{Milca Bomfim Conceição}

Graduada no curso de Produção Multimídia pela Unijorge (BA), atualmente estudando Ciências Contábeis (BA), atualmente atua como secretária no Centro Educacional Kadosh. Salvador, Bahia, Brasil 
Uilson de Freitas Fernandes

Designer Gráfico, Técnico de Imagem, Ilustrador, Modelador e Animador 3D, especialista em Produção Multimídia, Computação Gráfica e Game Designer nas horas vagas. Salvador, Bahia, Brasil 